\title{
Thermotropic properties of new electrochromic viologen-based ionic liquid crystals
}

\author{
Corrente G.A., Veltri, L., Beneduci A.
}

Department of Chemistry and Chemical Technologies, University of Calabria, Via P. Bucci, Cubo 15D, 87036 Arcavacata di Rende (CS), Italy

Email: giuseppina.corrente@unical.it
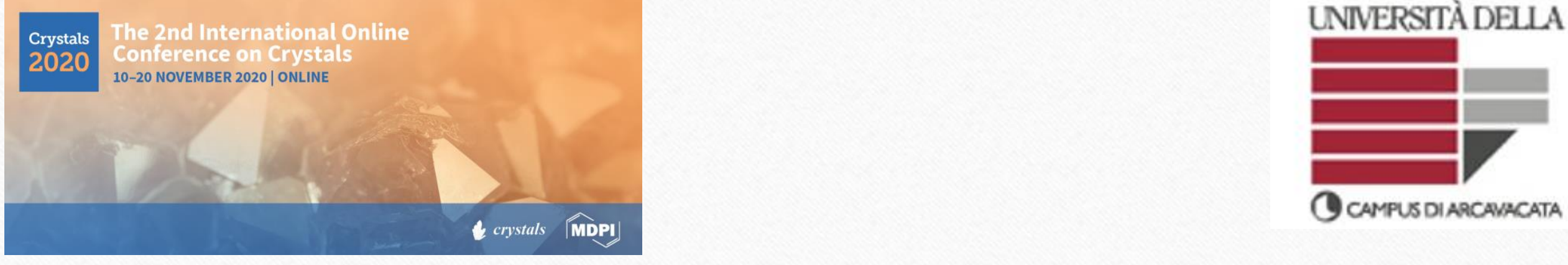


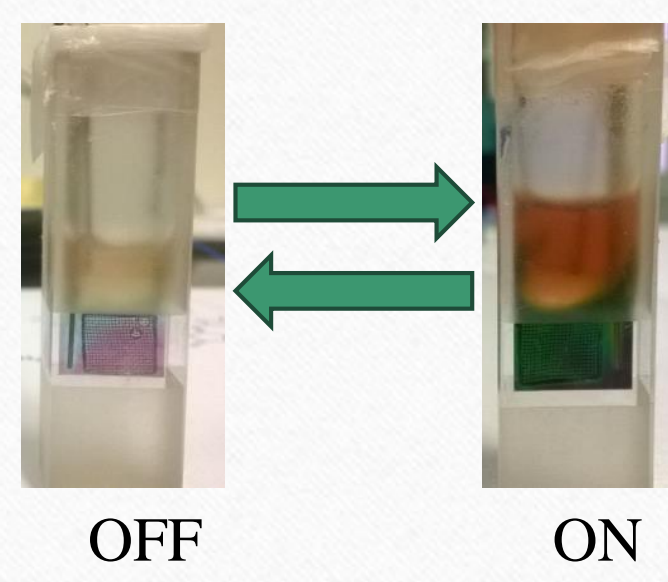

$>$ Multiple redox states

$>$ Many hues

$>$ Low potentials
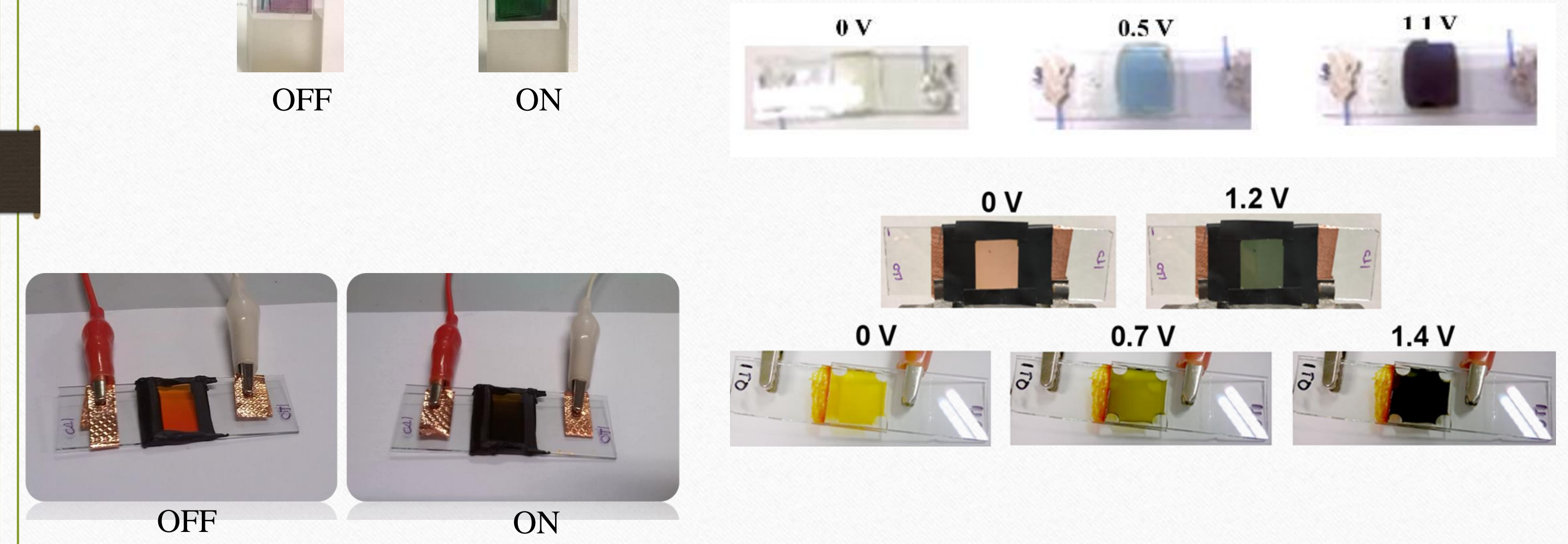
E-papers

$>$ Optical switching devices

$>$ Smart windows: light control

Camouflage materials

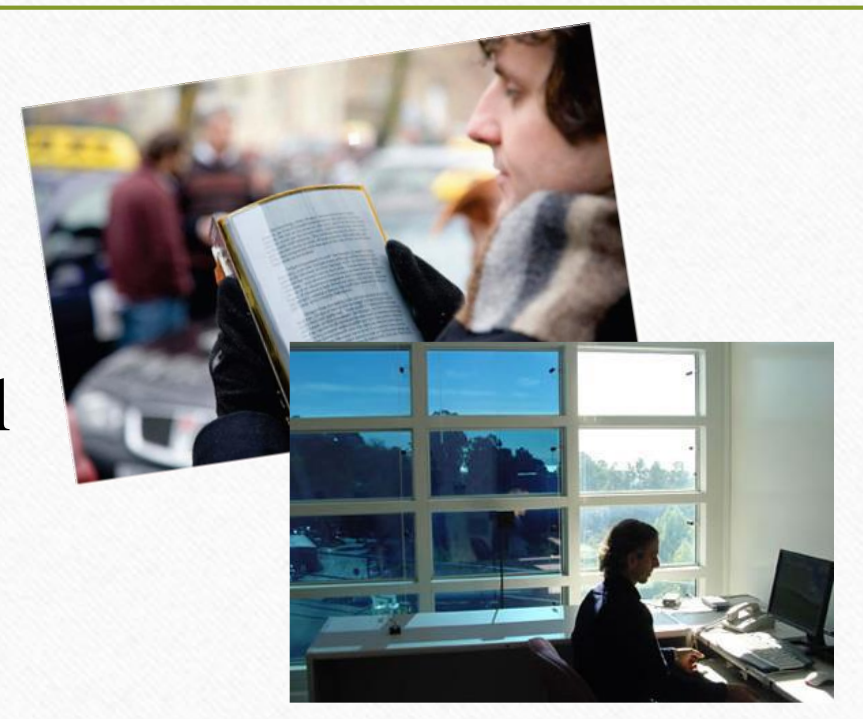

Optical communication

Data storage

Smart windows: thermal control

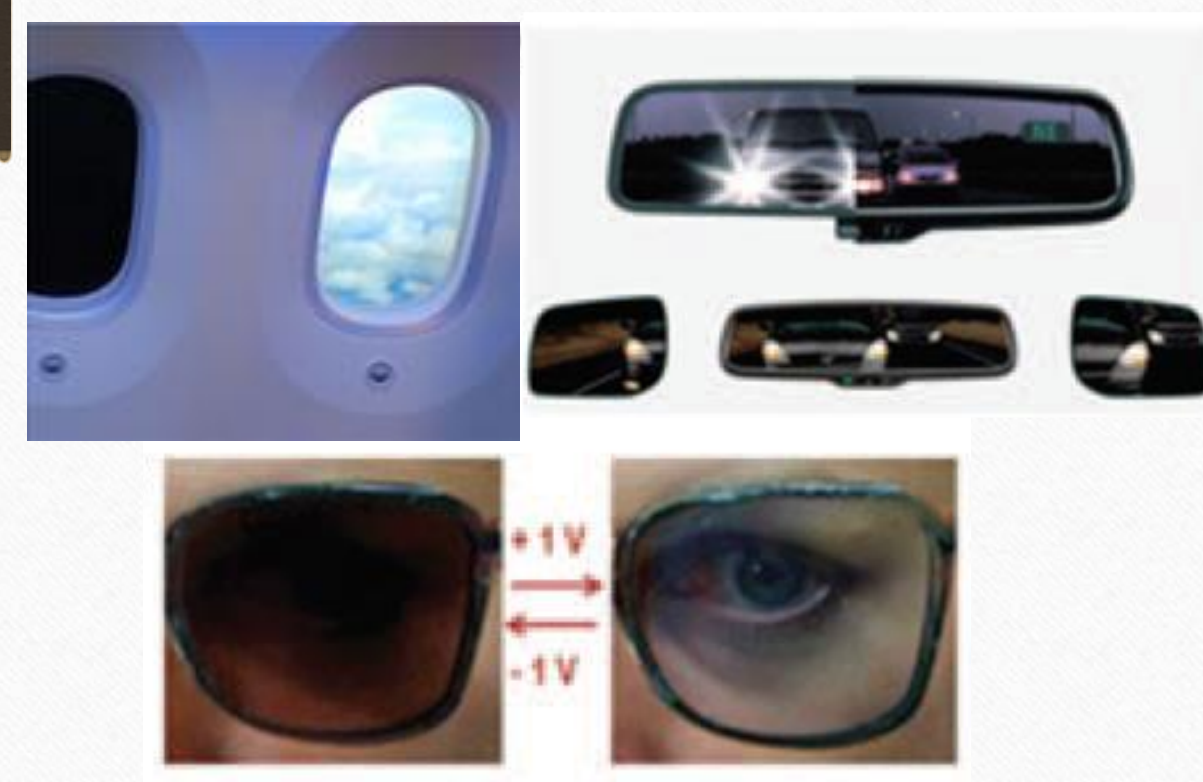

Electrochromic windows

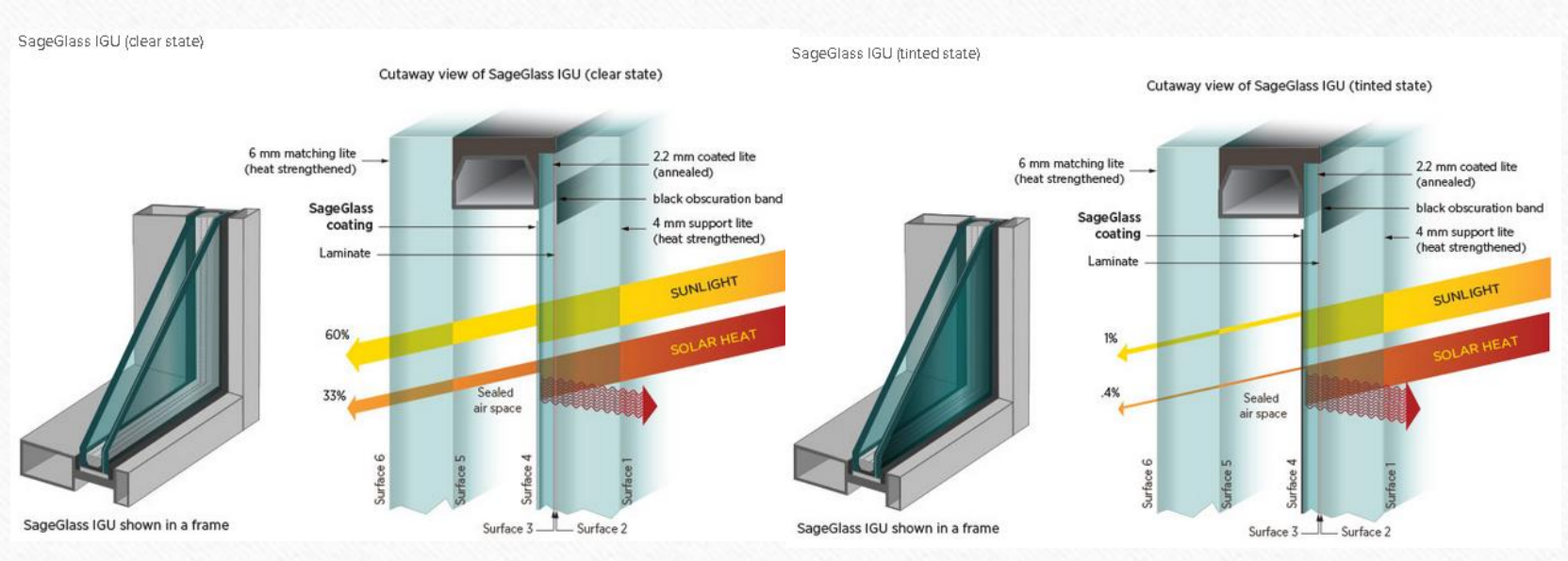




\section{Electrochromic Devices and Properties}

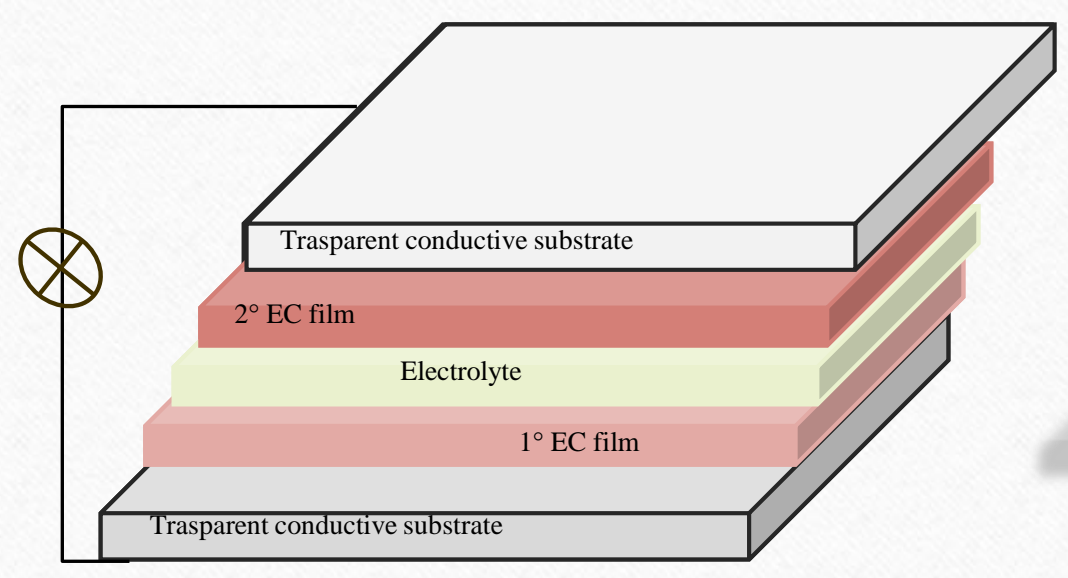

hermoplastic polyme

Over the electro-active, -chromic species

$\checkmark$ high ionic conductivity,

$\checkmark$ ideal zero electronic conductivity,

$\checkmark$ large electrochemical windows,

$\checkmark$ fast ion mobility during redox events,

$\checkmark$ low volatility,

$\checkmark$ thermal and environmental stability 


\section{RIEDOX ACTIVE LIQUUD CRYSTALS (LCS)}

LCs are characterized by the integration of ionic and electronic functions.

Ion conduction can be obtained by doping the LC or by covalent attachment to LC

\section{IONIC LIQUIII CIRISTILS (IILCS)}

Mesomorphic salts where, in most cases, the mesogenic part exists as an organic cation (substituted pyridinium, bipyridinium, imidazolium, phosphonium, etc.). Bulk ion conductivity in these materials, which can be as high as $10^{-2} \mathrm{~S} \mathrm{~cm}^{-1}$, is due to the nanosegregation between insulating layers made of long promesogenic alkyl chains and conducting layers bearing the ionic moiety. 


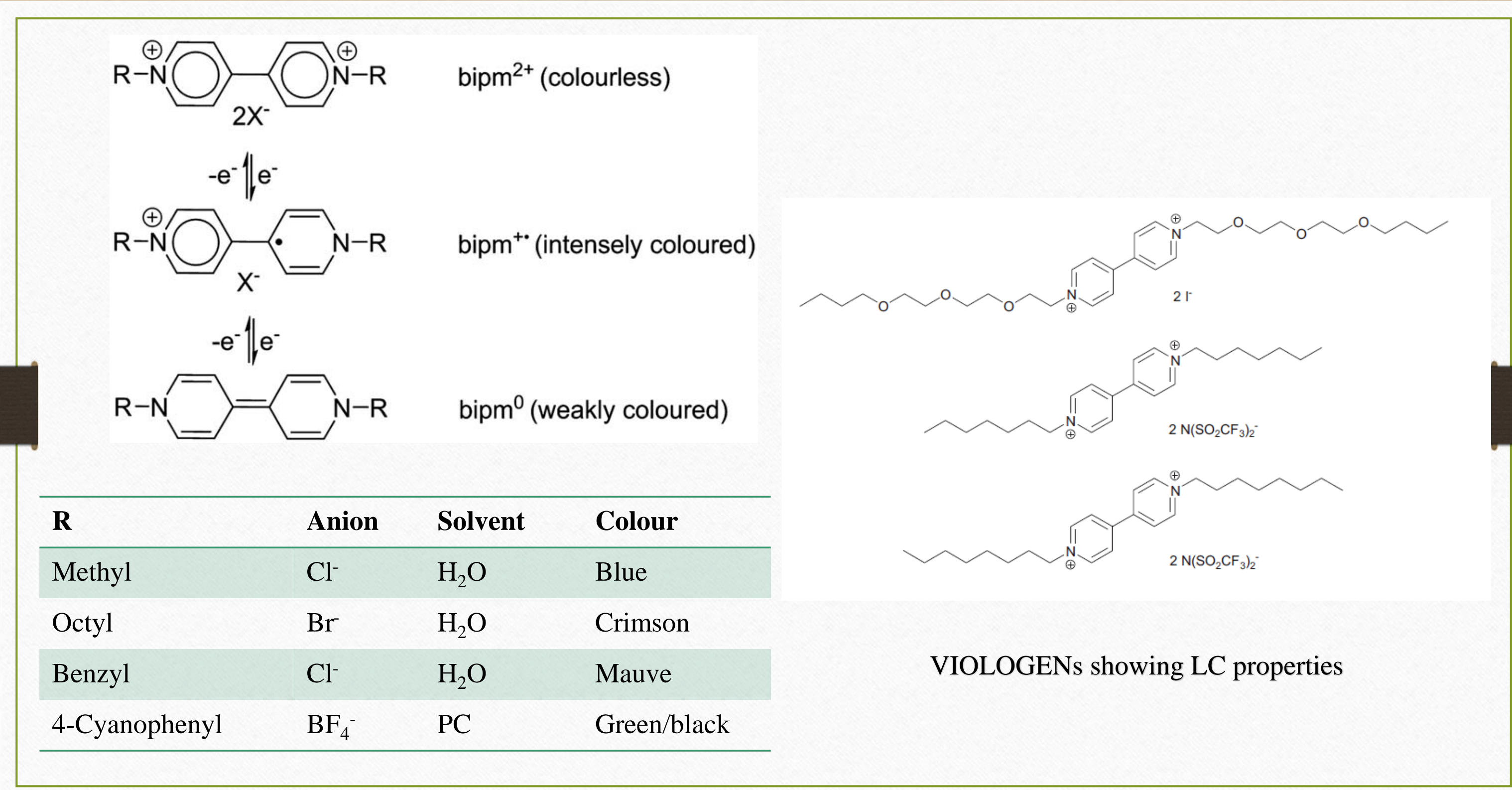




\section{Extended viologen as electrochromic ILCs}
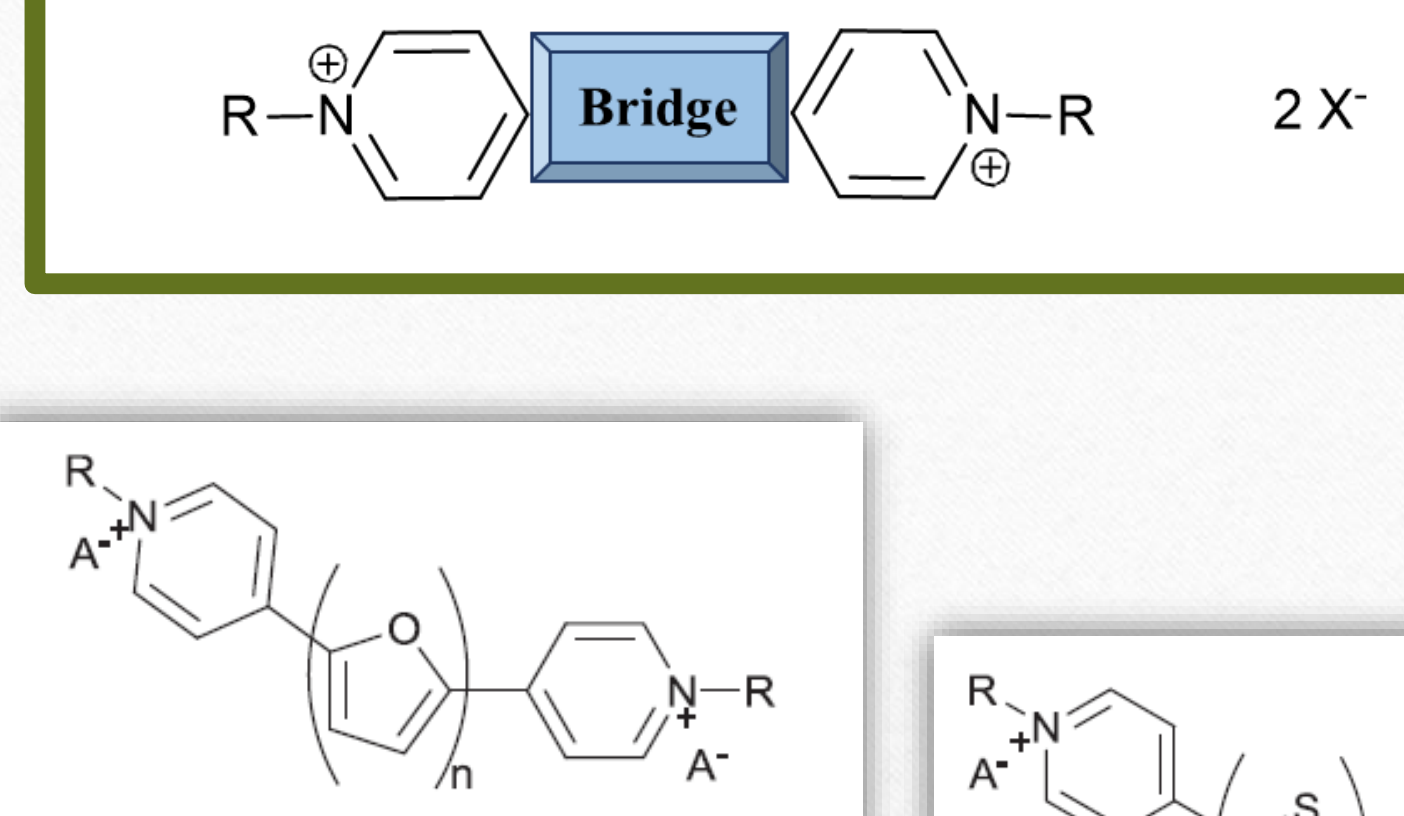

$\mathrm{n}=1,2$

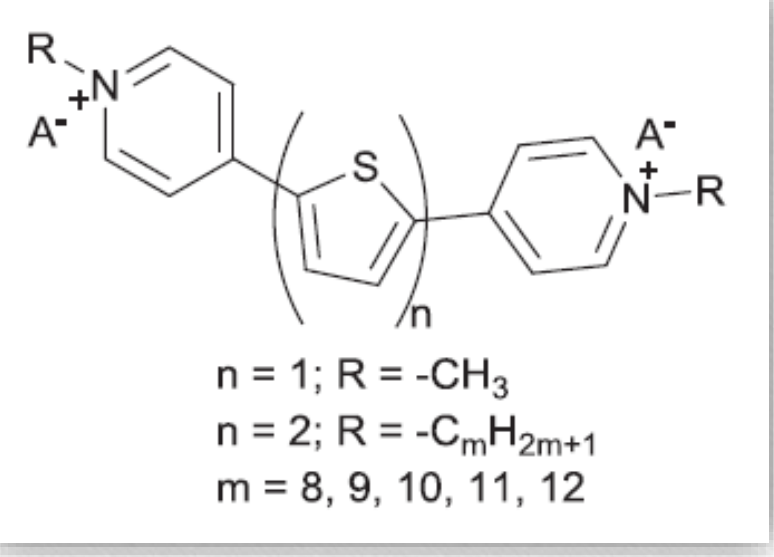

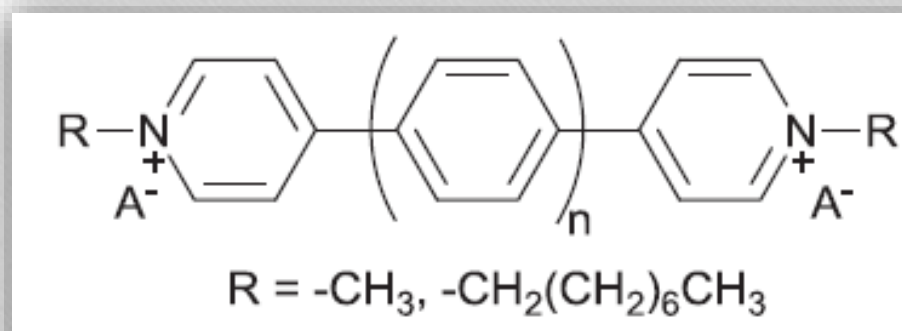
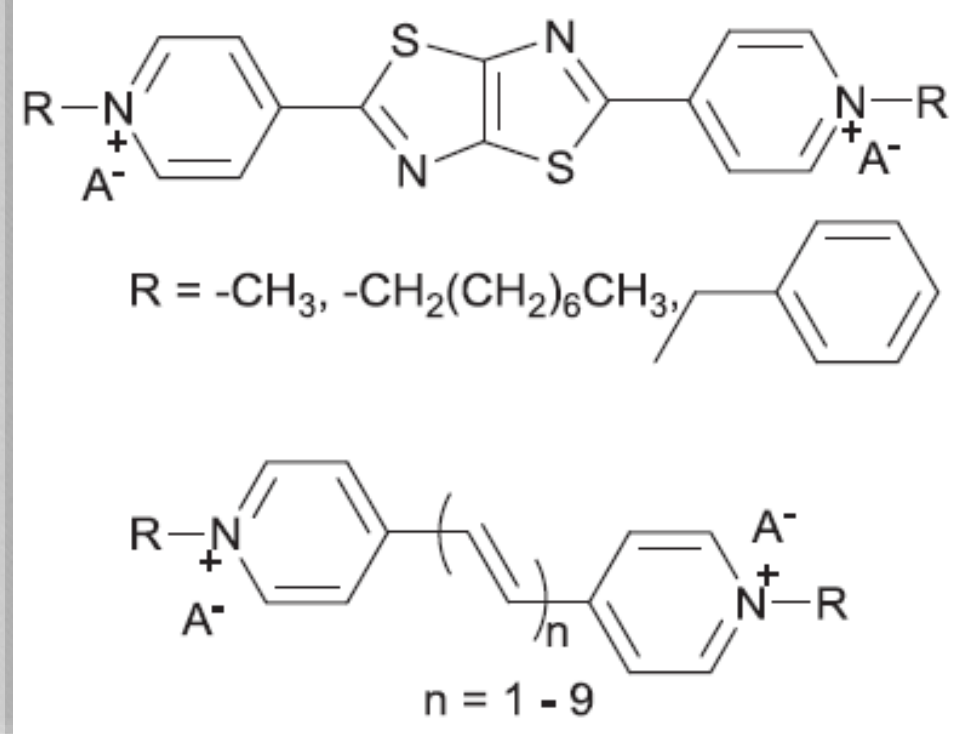

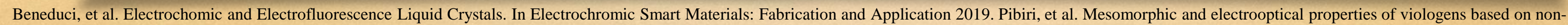


Mono-substituted viologen Bis-substituted viologen

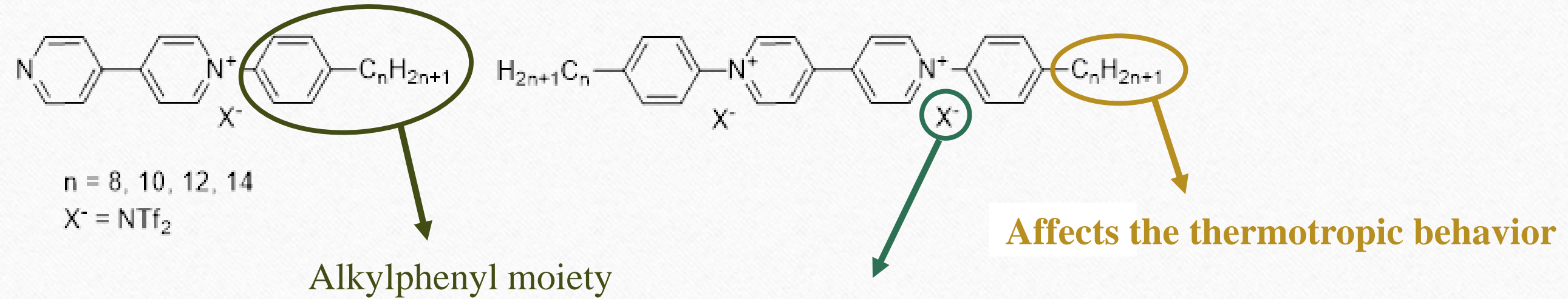

Affects the thermotropic behavior

Bulk electrochemical properties 


\section{POM investigation}

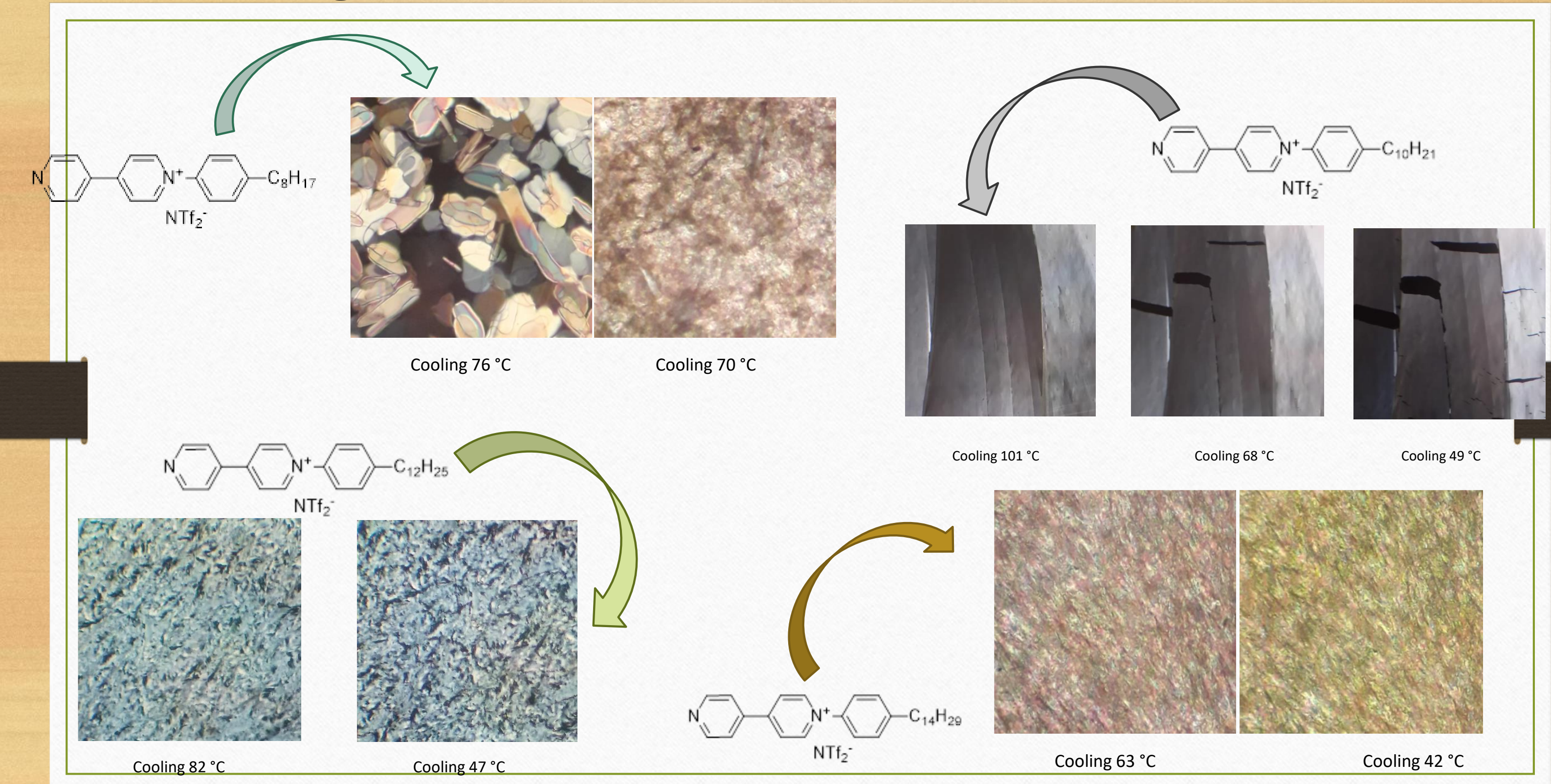




\section{Transition temperatures}

\begin{tabular}{|c|c|c|}
\hline Sample & $\begin{array}{l}\text { Temperature }\left({ }^{\circ} \mathrm{C}\right) \text { of } \\
\text { transition }\end{array}$ & $\mathbf{T}_{\text {clearing }}\left({ }^{\circ} \mathrm{C}\right)$ \\
\hline $\mathrm{M} 8-\mathrm{NTf}_{2}$ & $108-72$ & 130 \\
\hline M 10-NTf 2 & $101-68$ & 117 \\
\hline M 12-NTf ${ }_{2}$ & $84-63$ & 119 \\
\hline $\mathrm{M} 14-\mathrm{NTf}_{2}$ & $\begin{array}{l}84-67 \\
67-40\end{array}$ & 116 \\
\hline D 8-NTf 2 & $66-17$ & 194 \\
\hline D $10-\mathrm{NTf}_{2}$ & $83-61$ & 175 \\
\hline D 12-NTf 2 & $\begin{array}{l}273-74 \\
74-54\end{array}$ & 293 \\
\hline D 14-NTf 2 & $310-80$ & 314 \\
\hline
\end{tabular}




\section{POM investigation}

$\mathrm{C}_{8} \mathrm{H}_{1}+\underbrace{-}_{\mathrm{NTf}_{2}^{-}}$

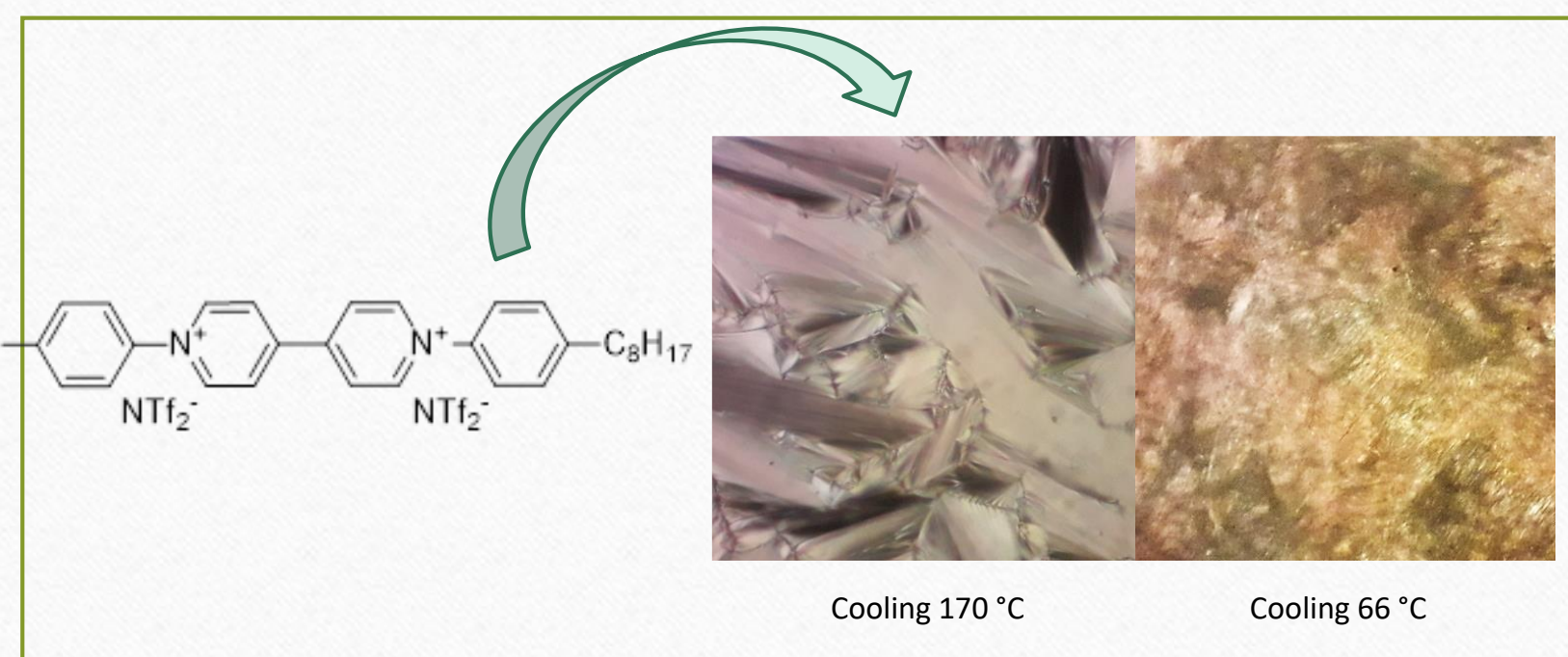

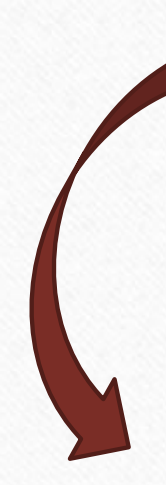

$\mathrm{C}_{10} \mathrm{H}_{21}-$

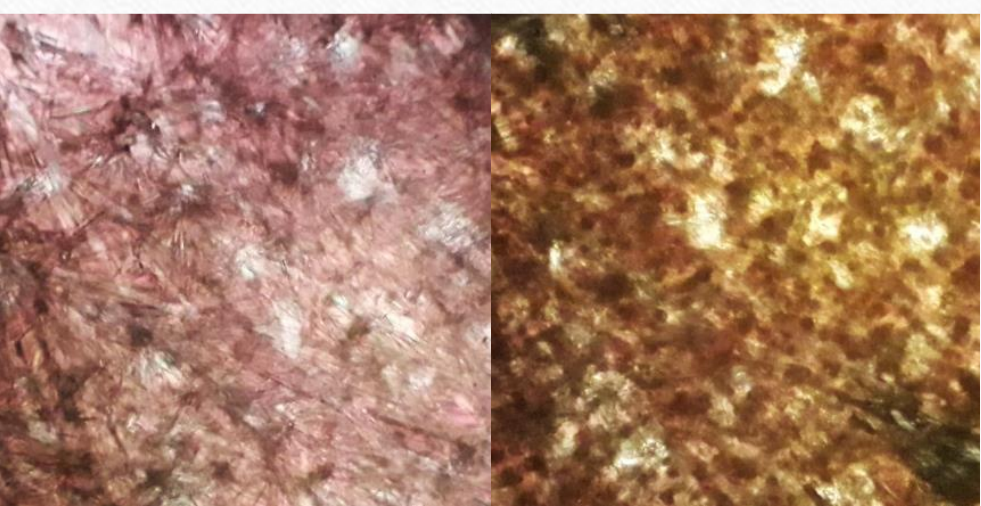

Cooling $74^{\circ} \mathrm{C}$

Cooling $47^{\circ} \mathrm{C}$
$\mathrm{C}_{12} \mathrm{H}_{25}-$

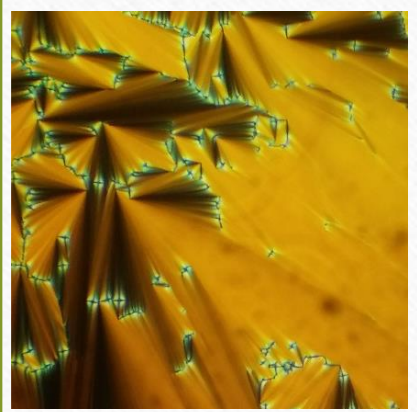

Cooling $273^{\circ} \mathrm{C}$

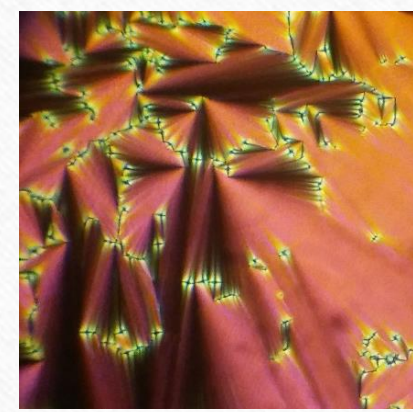

Cooling $74^{\circ} \mathrm{C}$

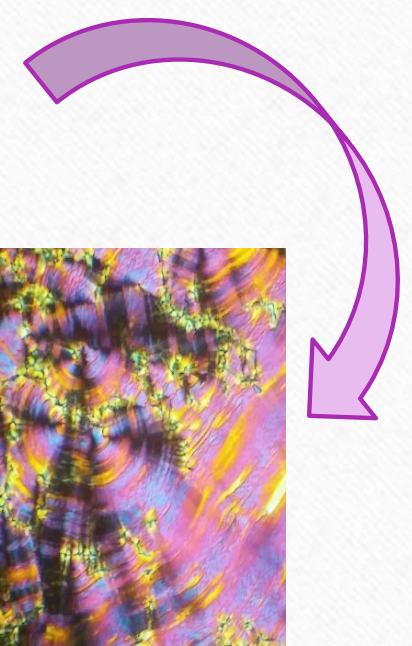

Cooling $54^{\circ} \mathrm{C}$

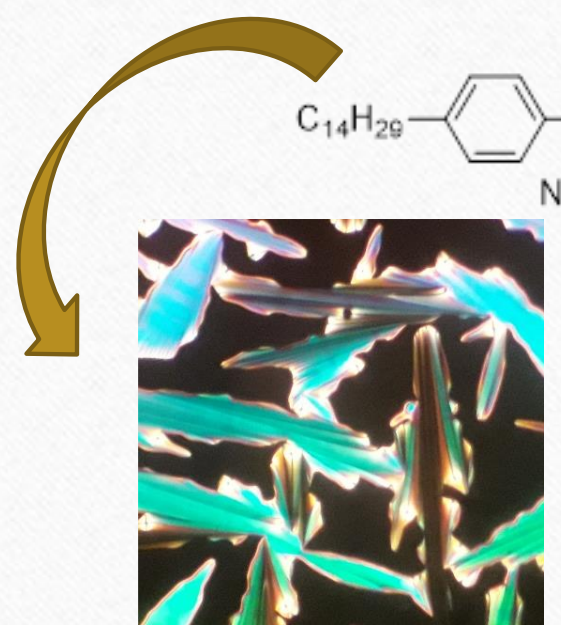

Cooling $296^{\circ} \mathrm{C}$

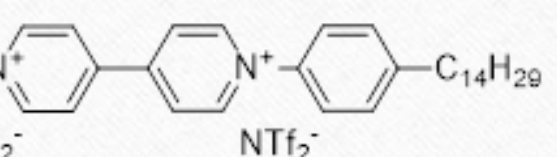

$\mathrm{NTf}_{2}$.

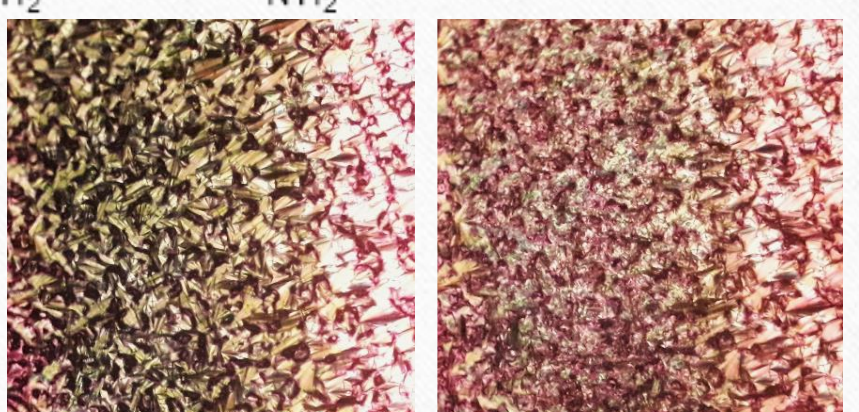

Cooling $122^{\circ} \mathrm{C}$ 


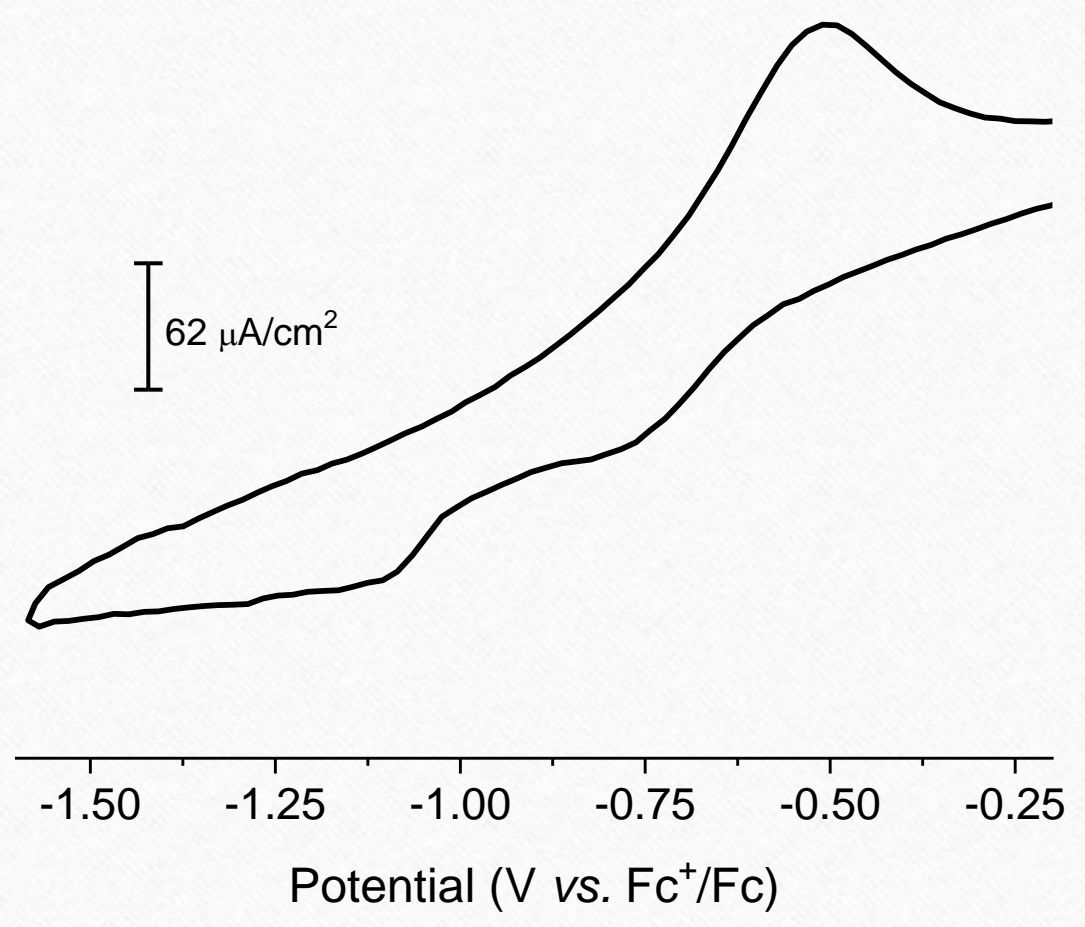

Cyclic voltammetry of 8-NTf 2 as representative redox behaviour of alkyl-based phenyl-viologens in $\mathrm{PC} \mathrm{TBAPF}_{6}$

$$
(0.1 \mathrm{M}) \text { at } 1000 \mathrm{mV} / \mathrm{s} \text {. }
$$

The redox processes occur at more positive potentials with respect to classic viologens.
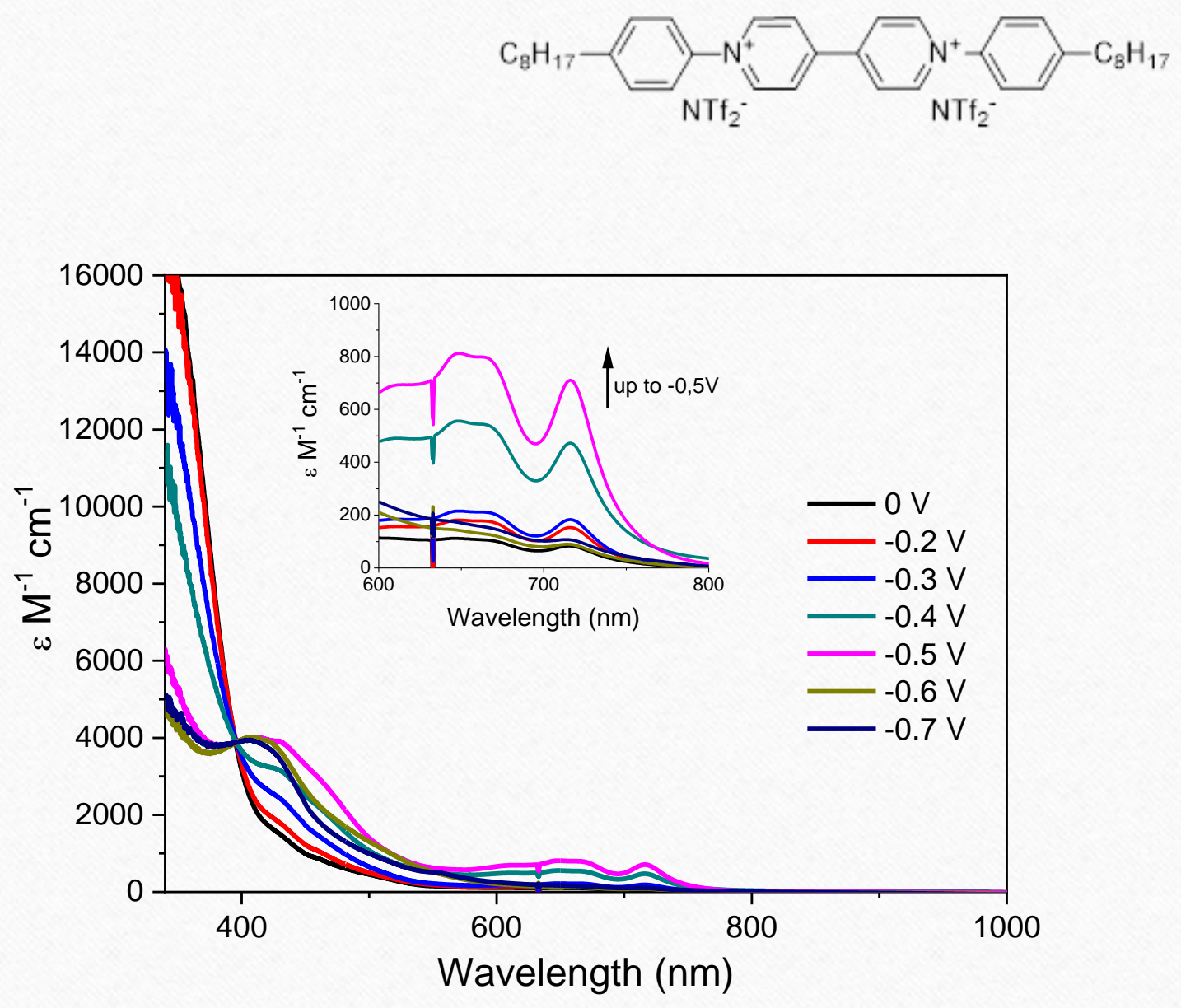

Spectroelectrochemistry of the compound $14-\mathrm{NTf}_{2}$ with potential referred to $\mathrm{Ag} / \mathrm{AgCl}$. The inset, zooming the range $600-800 \mathrm{~nm}$, show the viologen absorbtion bands. 


\section{Bulk electrochromic properties}

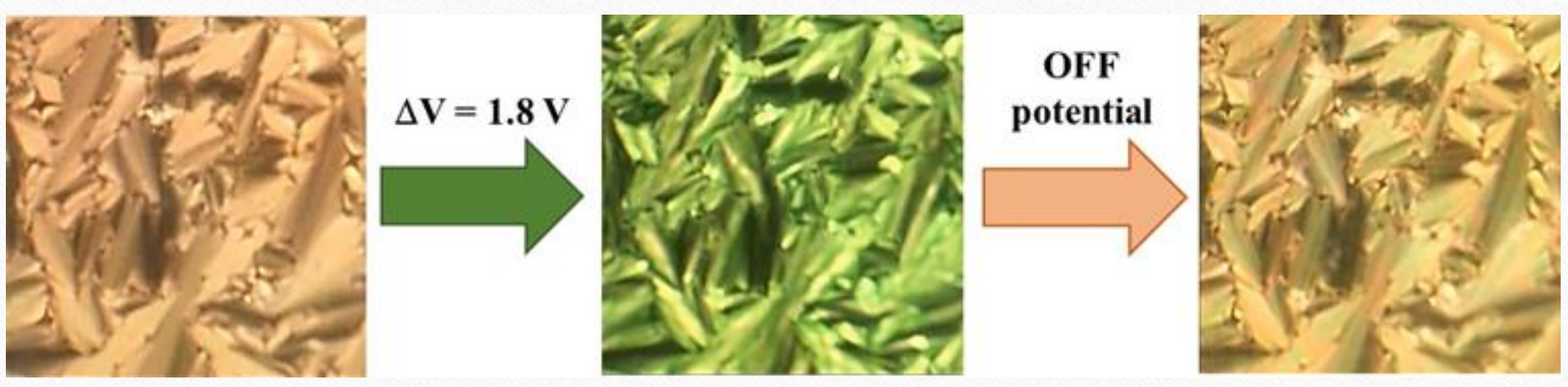

POM images of a thin film $(5 \mu \mathrm{m})$ of $8-\mathrm{NTf}_{2}$ sandwiched in a liquid crystalline cell, acquired during the reduction process as a function of the applied voltage difference

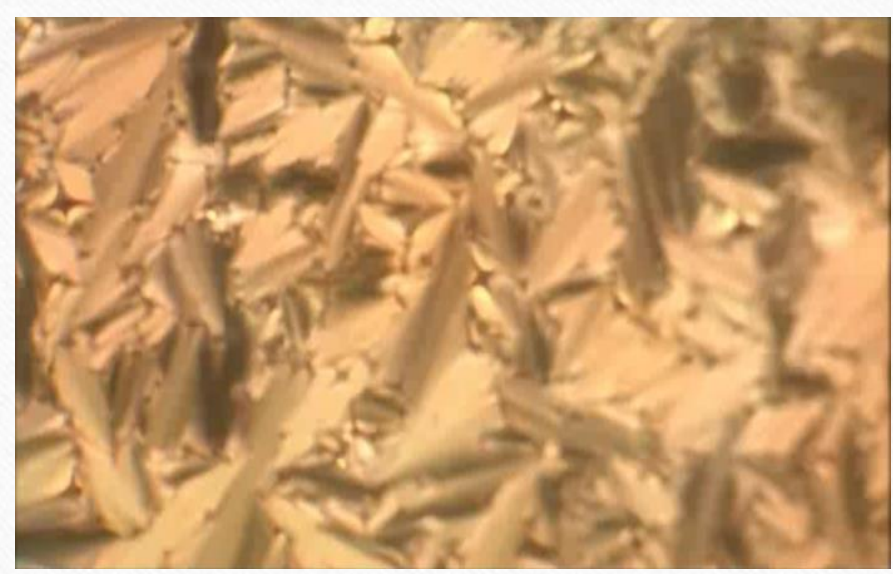


$\checkmark$ Two new sets of mono- and di-substituted viologens having electrochromic and electron accepting properties have been successfully characterized.

$\checkmark$ All the viologens exhibit a liquid-crystalline phase. Many of them show low crystal-to-smectic phase transition under $100^{\circ} \mathrm{C}$ while almost all have a wide range of LC phase.

$\checkmark$ These characteristics make such materials suitable for the development of new high performance devices (opto-electronic devices), since they exhibit LC mesophases with a good reversibility and with an high fluidity. 


\section{THANK YQU FOR YOUR KIND ATTENTION}
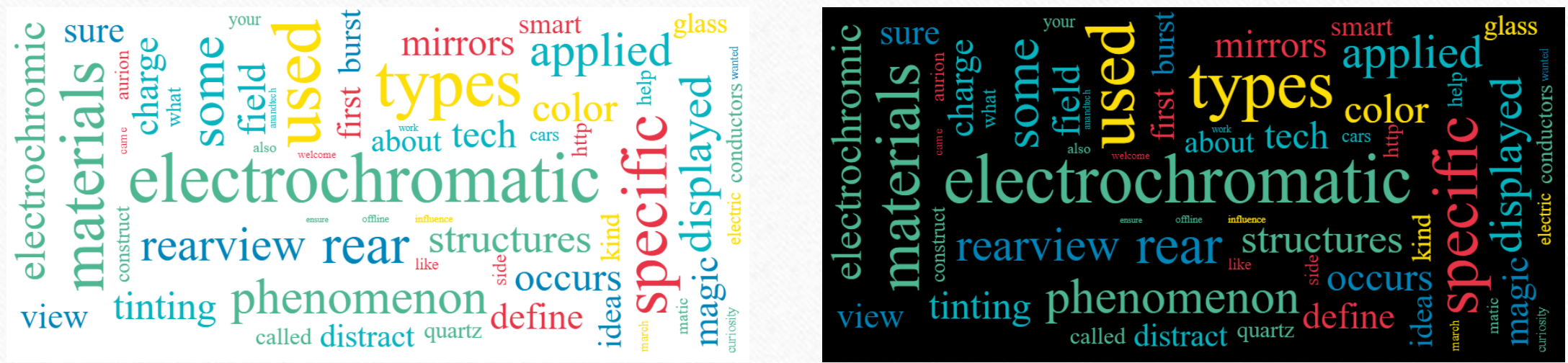